\section{INDIGENOUS FORESTS OF NEW ZEALAND}

$I^{\mathrm{T}}$ $T$ is rather illuminating to realize that some of our English characteristics are just as strong in a Dominion. The 'hands off the New Forest' controversy when the Forestry Commission suggested. undertaking certain operations will be remembered. Beauty spots in that region or elsewhere in Great Britain may chiefly depend upon the presence of a clump or block of old trees-very beautiful things. The argument is that it would be desecration to touch them. Since the trees will not stand for ever, this means that our children or grandchildren will never see that particular beauty spot.

In the report for 1944 of the New Zealand State Forest Service (Gov. Printer, Wellington, 1944) the attitude has arisen on a larger scale. New Zealand has still left a considerable area of its old indigenous forests, although exotic conifers have been planted on a very extensive scale. Arising from the admirable soil conservation schemes now under consideration in the Dominion is one aspect which constitutes a serious threat to these national forests. It is the 'hands off' policy once again. "Well meaning but unrealistic enthusiasts," says the report, "advocate a lock-upuse-not policy of forest reservation, under the mistaken impression that such a practice will perpetuate the principal indigenous species-such as rimu, matai, etc. The exact reverse would occur in most forests. Why do so many of our rimu forests consist of virtually only old trees with seedlings and medium. age trees so few as to be insignificant? The initial cause is the fact that, no matter how prolifically the old trees seed, the humus on the floor is so thick that even when the seeds germinste, roots are seldom able to penetrate to the mineral soil beneath, and most seedlings therefore die." The Director of Forestry, continuing, points out that owing to the density of shade such seedlings as do develop gradually die from want of light, while in other parts of the forests inferior species capable of standing more shade are ousting the more valuable ones.

The Director deals with the whole matter clearly, giving a sylvicultural exposition with which a forestry student is well acquainted at the end of his first year's study - data so little known in spite of their elementary nature that ignorance thereof is imperilling the future of the Dominion's indigenous forests. Controlled logging and fire protection are advocated as the methods to be introduced. It is the logging, that is, felling any of the trees, which the opponents object to. The answer is a condemned and disappearing forest.

In connexion with this logging in indigenous forest, an almost inevitable discovery has been made, meriting consideration outside New Zealand. New plywood factories were to provide plywood for defence works and a junior technical officer of the Forest Service was stationed at one of these to assist in the solution of current problems in the manufacture of both casein- and resin-bonded plywood for defence works. Marked advances in manufacturing technique have been made, but there is said to be room for improvement. The tentative conclusion has been arrived at that the high moisture content of rimu and other indigenous logs makes it extremely difficult to dry their veneers in standard driers and at the rates, temperatures and humidities usually employed in plywood manufacture. On the subject of peeler-logs, it has been established that the quality of the local product, if it is to compete successfully with imported plywoods on a quality basis, will have to be improved. Straightness of grain and reasonable freedom from defects are essential to the production of sheets free from twist and warp, etc.

This applies equally to the logs used in the plywood mills in Britain, where most of the material used is imported. It is the forest officer's business to seo that only suitable logs are ear-marked for plywood conversion. As to the standard driers, New Zealand might learn something in this direction from India, at the Forest Research Institute, Dehra Dun; for departures from European practice both in pattern of drier, temperatures, humidities and length of time of remaining in the drier are in practice in that country.

E. P. Stebring

\section{BRITISH ARMY VETERINARY SERVICES IN THE FAR EAST}

A PREVIOUS note (Nature, Jan. 13, 1945, p. 60) described the great responsibilities and high quality of the work of the Army Veterinary Services in the Near East. In the Far East, says Brigadier E. S. W. Peatt (Vet. Record, May 12, 1945, p. 219), even greater responsibilities are being undertaken. The campaign in Burma made necessary a return to animal transport, and this fact, together with the duty of providing fresh meat for the troops, made necessary an organization for the care of a great variety of animals. The result has been that the British and Indian veterinary personnel has increased to ten times its pre-war strength and further increases are likely.

Adequate training in veterinary tropical medicine was an early problem, and in October 1942 the Indian Army Veterinary Corps Training Centre was estab. lished. Its Officers' 'Training School now gives a training lasting two months to fifty officers at a time and its training wing gives to 1,200 men at a time a course lasting five months. Both courses are designed to produce competent soldiers as well as competent veterinary personnel, because the necessity of military as well as veterinary training has often been demon. strated in the fighting in Burma and Arakan. Farriers are trained in the Army Veterinary School; the classes consist of twenty-four students and extend over sixteen weeks, this training being continuous throughout the year. The same School gives con. tinuous instruction in veterinary first-aid, animal management and the care of cattle, sheep and goats purchased for slaughter.

The care of transport animals used for military purposes involves the care of horses, mules and donkeys used in operational areas; the care of bullocks used on peace stations so that horses and mules can be released for operational work; the care of the camels, which are restricted by climatic conditions to the North-West Frontier and the Punjab; and the care of elephants used in the Burmese jungle. But, in addition to all this work, the Army Veterinary Service has the important responsibility of the control of the military dairy farms, and it has been necessary to set up a separate veterinary organization to deal with these. The Military Dairy Farms Department has increased its milch cattle from 10,000 to more than 60,000, and to-day it is probably the biggest 
dairy organization in the world. Although there are 290 million cattle in India, the provision of fresh meat for the troops is made more than usually difficult by the climate, the enormous distances involved, the many infectious diseases and the fact that Indian animals are not bred and fattened for slaughter. Several hundred thousand animals are bought each year for slaughter, and the Army Veterinary Service examines and selects them and cares for their health. Many animals must spend from three to ten days in the train before they reach their destinations. Slaughter stock are transported by sea voyages which may last from one to five days, by train, by motor, on foot or by a combination of all four methods; and the hot weather, traffic congestion, compulsory use of all-metal wagons and other factors increase the difficultios of organizing such journeys. Animals are never kept in the train for longer than forty-eight hours; but the rests between spells of travelling expose them to the many infectious diseases of the Far East.

A further responsibility of the Army Veterinary Service is the breeding, through local development schemes, of pigs, rabbits and poultry, and these animals present their own disease problems. The Army Veterinary Service also inspects the meat and provides the Veterinary Wing of the Chemical Defence Research Establishment, which deals with the defence of animals against gas warfare. The Army Veterinary Laboratory Services and their mobile laboratories prepare vaccines and undertake routine and other diagnostic work. Nowhere else in the world, says Brigadier Peatt, does the veterinary officer encounter such a variety of diseases. A good example of the military importance of these diseases is the outbreak of the equine trypanosomiasis called 'surra' in 1942 on the Assam-Burma border. At one time 17 per cent of the horses and mules were put out of action by this disease, but the control measures adopted reduced the percentage of infected animals from 17 per cent in 1942 to 7 per cent in 1943 and 2 per cent in 1944. The Army Veterinary Service devised the method of injecting 'Antrypol' intravenously and obtained by this method 90 per cent of recoveries from this disease. Anti-surra units have now been formed.

Two other important diseases are anthrax and rinderpest, against both of which all cattle purchased and many sheep and goats are immunized. Rinderpest is the most important cattle disease in India. Although many thousands of cattle owned by civilians have died near the military dairy farms, the losses on these farms have been negligible (less than 1 per cent in 1943-44). Outbreaks of glanders have been quickly controlled, epizootic lymphengitis and strangles are being studied, precautions against foot-and-mouth disease, which is extremely widespread in India, are being taken, and the control of variola, which is usually introduced to dairy farms by buffaloes which have been bought, is being improved. Among the serious diseases of the smaller animals are pasteurellosis, salmonellosis and Ranikhet (Newcastle or Doyle's disease), and research upon the control of these is being done.

It is clear that the Army Veterinary Service is doing in the Far East a fine job which is vital to the success of the war against Japan. The quiet efficiency and progressive spirit of this work show how much the veterinary profession can contribute to the solution of the vast food problems of the post-war world.

\section{ARTS AND CRAFTS OF THE COOK ISLANDS}

$T N$ a large and profusely illustrated volume the 1 Director of the Bishop Museum gives a comprehensive and detailed account of the material culture of the Cook Islands*. The Polynesians are known for their clever workmanship and, as the illustrations show, these islanders are no exception, whether they are carving wood or plaiting fibres. The greater portion of the book is concerned with a description of the arts and crafts, including religious symbols, and this is followed by a discussion of their implications.

A study of the material culture of the Cook Islands shows that there are three cultural periods, a fact that may be best understood by the racial history of its inhabitants. The Polynesian ancestors, as it is now recognized, came from the mainland of Asia into Indonesia where they adjusted their continental culture to suit volcanic islands the fertile soil of which produced abundant food and where a rich culture developed. From Indonesia they passed on to Micronesia, the coral atolls of which formed a barren contrast; arts and crafts suffered drastic changes owing to the loss of food plants and raw material of wood and stone, and the people retrogressed from the stone age to a shell age. From here these ancestors, in the course of ages, moved westwards and finally arrived at the Society Islands, where they were once more on volcanic soil, so that stone was again available and the rich soil provided ample food. On these islands the Polynesians settled and from them they radiated out to the various island groups they were destined to colonize. They rediscovered the use of stone, and food plants and animals were probably introduced from the Melanesians in Fiji.

It was in this period of expansion that the Cook Islands were settled-roughly six hundred years ago - the culture being identical with that of the parent colony of the Society Islands, and this forms the first phase. Modifications and local developments have naturally taken place in both island groups so that it is difficult to give an exact picture of this early stage, but certain elements can be reconstructed. Some cultural processes, which may be regarded as stable, persisted unchanged until European occupation; examples of these are the plough method of firemaking and the earth-oven. The second period was one of developments rather than of any very sudden change. These may be due to diffusion owing to migration or importation or they may be caused by the substitution of another material or technique. Occasionally a new local technique is invented, such as the decorated borders to the pandanus sleeping mats that are peculiar to the Cook Islands.

The third period begins with the arrival of the white people. Early European voyagers bartered hoop iron and axes for fresh food, and the natives were quick to realize the superiority of metal over stone and to acquire it whenever possible. With the coming of the missionaries clothing was altered both in design and in material, and as timge went on most of the old culture became obsolete. The new generation has grown up under these changed conditions and the cultural invasion is firmly established, for the natives will not give up the material comforts of to-day for any mental satisfaction connected with a sentimental past. K. RISHBETH.

- Arts and Crafts of the Cook Islands. By Te Rangl Hiroa (Peter H. Buck), Bernice P. Bishop Museum Bull. 179 (1944), 